\title{
REFLEXOS DO MEDO E DA INSEGURANÇA NA REALIDADE E NO COTIDIANO DA JUVENTUDE BRASILEIRA
}

\section{Edson Benedito Rondon Filho Tatiana Sampaio de Sampaio de Souza}

\section{RESUMO}

O presente artigo realiza uma abordagem compreensiva quanto à situação de risco social a que muitos jovens brasileiros são submetidos diariamente, e tem como objetivo demonstrar os reflexos desta realidade em seu comportamento e em seu cotidiano, considerando sua convivência com a constante sensação de medo e insegurança. A principal consideração deste ensaio é que os fatores de risco social podem ser encontrados em jovens de qualquer classe social, porém nas classes mais vulneráveis economicamente existe, concomitante a esta situação, a dificuldade de acesso aos meios necessários para lidar com as consequências da situação de risco, o que acaba se refletindo no comportamento dos sujeitos envolvidos e em seus planos para o futuro.

Palavras chave: Risco. Insegurança. Medo. Juventude. 


\section{INTRODUÇÃO}

A fase da juventude é marcada por intensas transformações biológicas (físicas), psicológicas e sociais que acabam por influenciar nas disposições dos indivíduos em sua vida adulta. Essas transformações acontecem a partir das socializações (primária e secundária) dos indivíduos.

A juventude (no caso, coincidindo sua temporalidade com a adolescência) possui a singularidade de ser uma fase de acentuado processo de desenvolvimento com desdobramentos nas relações dos jovens que se materializam com muito mais intensidade do que em qualquer outra fase da vida do ser humano. No caso de jovens que se encontram em situação de risco social, elementos externos contribuem em grande escala para acentuar todas essas transformações.

O objetivo principal deste ensaio é demonstrar os reflexos dos fatores de risco social no comportamento e no cotidiano dos jovens, considerando a constante sensação de medo e insegurança presentes em suas vidas. Para isso, realiza-se uma abordagem compreensiva quanto à situação de risco social a que muitos jovens brasileiros, quando crianças e adolescentes, são submetidos, aprofundando os aspectos de vulnerabilidade tangentes à criminalidade juvenil e à violência intrafamiliar.

Importante salientar que não se pretende esgotar o tema e que os resultados ora apresentados são parciais, sendo que a finalidade principal deste artigo consiste na ampliação do espaço de problematização e discussão sobre a situação de risco social da juventude brasileira e a sensação de medo e de insegurança com a qual convivem diariamente.

\section{JUVENTUDE: TENSÃO ENTRE O RISCO SOCIAL E O DESENVOLVIMENTO}

Os temas ligados à juventude interessam ou deveriam interessar a todos, pois, conforme aponta Tavares dos Santos, os jovens compõem grande parcela da sociedade: 
Considerando, em termos demográficos, a juventude como composta pela população de 15 a 24 anos, temos 27.083.758 de habitantes, $16 \%$ do total de 173.966.052 residentes no Brasil, em 2003. Se considerarmos os jovens até a idade de 29 anos, chegaríamos a uma parcela de $24 \%$ da população brasileira, ou seja, 41.250 .243 pessoas, em 2003. ${ }^{28}$

O autor chama atenção para as múltiplas faces da juventude brasileira, constituída de diversos tipos-ideais de acordo com seu perfil que envolve classe, cor ou etnia com as quais se identificam, ou em quais grupos culturais se reconhecem, podendo-se falar em:

A "juventude dourada", geralmente pertencendo às classes altas e classes médias altas e às etnias de cor branca e amarela;

A "juventude em instabilidade", composta por jovens, de modo amplo, que se situam nas classes média e média baixa, em sua maioria de cor branca e amarela, mas com uma parcela de negros e pardos; A "juventude trabalhadora", constituída por metade dos jovens entre 15 e 24 anos, o que significa cerca de 17.258.196 jovens, dos quais $37 \%$ recebiam até um salário mínimo (IBGE, 2004, p. 223);

A "juventude dos carentes", membros das classes populares, residindo nas periferias das grandes cidades, com diversidade de composição étnica (brancos, pardos, negros, indígenas);

A "juventude em vulnerabilidade": os "meninos de rua", membros das classes baixas, vivenciando processos de exclusão social nas médias e grandes cidades, também com diversidade de composição étnica (brancos, pardos, negros e indígenas);

A juventude dos "infratores", um grupo da população jovem pertencente a várias camadas

28 SANTOS, José Vicente Tavares dos. A agonia da vida: mortes violentas entre a juventude do país do futuro. In: Marcus Gonçalves da Cruz e Eduardo Cerqueira Batitucci (Org.). Homicídios no Brasil. Rio de Janeiro: FGV, 2007. p. 13. 
sociais e etnias, que cometeram delitos e passam a viver sob algum tipo de sanção penal. ${ }^{29}$

Esses tipos ideais não encerram a questão, mas marcam uma referência para se compreender o fenômeno com possibilidade de ocorrências de eventos cujas características são mesclas das disposições descritas e dependentes dos contextos sociais, marcando-se uma historicidade para cada sujeito integrante do fenômeno e que se apresenta em temporalidade e espacialidade particulares.

Podemos afirmar que os jovens passam por um processo de transição para a vida adulta, fase em que sua agressividade tem a positividade de habilitá-los a se autonomizar e a construir um lugar no espaço social, vivenciando um período de transformação entre a natureza, a tradição e a inovação $0^{30}$

Sobre as transformações ocorridas na fase da juventude, com ênfase na adolescência, Klosinski ${ }^{31}$ aponta uma metamorfose corporal, em que a puberdade vem acompanhada pela insegurança e pela instabilidade emocional, acarretando os problemas de ligação e desligamento da "casa paterna", em razão da forte influência do meio social.

No caso dos adolescentes em conflito com a lei ou em situação de risco social, essa fase de transformações vem acompanhada pelos aspectos de vulnerabilidade e risco presentes em suas vidas, destacando-se fatores sociais, familiares, econômicos e psicológicos, dentre algumas possibilidades.

O meio social afetado pelo processo de desenvolvimento não coincidente com os valores compartilhados conduz, cada vez mais, ao afastamento dos jovens das referências que até então eles seguiam e aceitavam. No contexto brasileiro, a omissão e a negligência dos responsáveis, a influência da criminalidade e, bem como, a grave diferença socioeconômica dificultam o bem estar e a afirmação dos jovens. Isso se torna mais visível no caso dos jovens de baixa renda, que muitas vezes se veem

29 SANTOS, José Vicente Tavares dos. A agonia da vida: mortes violentas entre a juventude do país do futuro. In: Marcus Gonçalves da Cruz e Eduardo Cerqueira Batitucci (Org.). Homicídios no Brasil. Rio de Janeiro: FGV, 2007. p. 13-14.

${ }^{30}$ Ibidem.

${ }^{31}$ KLOSINSKI, Gunther. A adolescência hoje: situações, conflitos e desafios. Tradução de Carlos Almeida Pereira. Petrópolis: Vozes, 2006. p. 11. 
fadados a um futuro pré-determinadolonge da escola e da educação por falta de condições e oportunidades.

Característica comum a muitos destes jovens é uma realidade permeada pela violência, não apenas física e psicológica, mas também social. Sabe-se que é enquanto criança e adolescente que o ser humano começa a formar sua personalidade, o que vai refletir em seus atos futuros em razão das disposições incorporadas nesse passado / presente. No entanto, nem todos nascem em lares harmônicos e convivem em espaços pacíficos; o que existe é um mundo onde crianças e adolescentes vivenciam cada vez mais cedo experiências de violências com as quais nem os adultos sabem lidar. Como exemplo de tal realidade, citam-se os casos de gravidez precoce, aborto, estupro, uso e tráfico de drogas, casos de violência física e psicológica, e a própria prática de atos infracionais.

Tavares dos Santos ${ }^{32}$ fala no desenvolvimento da violência como uma forma de sociabilidade, o que reflete diretamente no modelo de controle social adotado. A violência legítima forma de controle social de maneira aberta e contínua.

Dentro dessa realidade, muitos jovens estão a experimentar, cada vez mais cedo, todas as formas possíveis de violência, tanto como autores quanto como vítimas. E por sua situação peculiar de ser humano em intenso processo de desenvolvimento, as crianças e os adolescentes, em relação aos adultos, apresentam uma sensibilidade maior quanto às influências corruptoras do meio. Nesse ponto, destaca-se a reflexão de Abreu, que comenta acerca da vulnerabilidade nessa fase: ${ }^{33}$

Diante dessas fragilidades, a própria família que deveria atenuá-las, sendo imperfeita, não raro as agrava. E pode chegar a ser corruptora a ponto de conduzir o adolescente a práticas criminosas, às vezes desde a infância. Mais comumente negligencia na observância do relacionamento externo de seus filhos; ou, ao contrário, lhes impõe restrições excessivas, provocadoras de reações. Há enfim, os

\footnotetext{
32 SANTOS, José Vicente Tavares dos. A agonia da vida: mortes violentas entre a juventude do país do futuro. In: Marcus Gonçalves da Cruz e Eduardo Cerqueira Batitucci (Org.). Homicídios no Brasil. Rio de Janeiro: FGV, 2007. p. 68.

${ }^{33}$ FONSECA, Dirce Mendes da.O discurso de proteção e as políticas públicas sociais para infância e juventude.Revista Jurídica, Brasília, v.9, n.85, p. 73-82, jun./jul.2007. p. 73 .
} 
lares miseráveis, tumultuados, conflitantes e insuportáveis, á estimularem, pelo menos, as fugas dos filhos. ${ }^{34}$

Cabe salientar que esses fatores de risco não são encontrados de forma única e exclusiva nas classes desfavorecidas. Centurião afirma que:

É sabido, mesmo de modo empírico, em virtude da falta de estudos mais concretos, que as famílias de classe média, por exemplo, não são isentas de tais modelos de conduta. O que varia é o fato sobejamente conhecido da visibilidade social. Além disso, os grupos sociais de classe média podem apelar para atenuações, por assim dizer, que deem maior aceitação social a comportamentos que, nos menores de rua, ou oriundos das classes baixas em geral, seriam vistos de um modo mais negativo. Desse modo, para menores de classe média pode-se falar, frente a condutas tidas como desviantes, em "crise da adolescência". Este tipo de classificação dificilmente encontraria rejeição social, sendo considerada uma etapa normal, se bem que turbulenta, no processo de desenvolvimento psíquico. Pelo contrário, tal classificação induziria a uma atitude compreensiva. No entanto, para os menores das classes inferiores, a atribuição de padrões criminais ou antissociais de um modo geral, que não são substantivamente diferentes em relação à dos adolescentes de classe média é, geralmente, automática e imediata. ${ }^{35}$

Assim, a situação de risco social a que crianças e adolescentes são constantemente submetidos em nossa sociedade é uma condição que envolve os mais variados fatores, e pode ocorrer em qualquer classe social. A intensidade desse risco surtirá efeito de acordo com os aspectos de

\footnotetext{
${ }^{34}$ ABREU, Waldir de. A corrupção penal infanto-juvenil. Rio de Janeiro: Forense, 1995. p. 12.

${ }^{35}$ CENTURIÃO, Luiz Ricardo Michaelsen. Alguns aspectos do menor de rua e seu contexto. In: GAUER, Gabriel José Chittó; GAUER, Ruth Maria Chittó (ORG.). A
} femenologia da violência. Curitiba: Juruá, 1999. p. 72. 
vulnerabilidade à criminalidade juvenil e exposições à violência intra e extrafamiliar a que esses sujeitos são submetidos, o que marca a tensão entre o seu desenvolvimento e os riscos sociais a que são submetidos.

\section{ASPECTOS DE VULNERABILIDADE E CRIMINALIDADE JUVENIL}

No caso do atendimento aos adolescentes em situação de risco ou vulnerabilidade social, a compreensão de conteúdos sociológicos, biológicos, psicológicos, econômicos e familiares, que giram em torno da vida destes jovens é de suma importância. Para Centurião, o profissional que se dedica a trabalhar com crianças e adolescentes deve possuir uma perspicácia psicológica capaz de lhe fornecer o suporte necessário para compreender a realidade dos mesmos. ${ }^{36}$

Sobre a amplitude do conceito de delinquência juvenil e o perfil do profissional que com ela trabalha, Trindade declara que:

A primeira constatação é, portanto, da impossibilidade de uma definição geral e unívoca. A segunda é que a ambiguidade da expressão nos coloca frente a várias dificuldades. A terceira, que conviver com essas dificuldades não é, necessariamente, uma limitação. Ao contrário, suportar as diferenças é uma das qualidades que deve ter quem pretende lidar com a delinquência juvenil. ${ }^{37}$

O termo delinquência abarca mais de uma concepção. Compreende uma posição legalista e outras de cunho sociológico, psicológico, psiquiátrico, biológico, etc. No entanto tais concepções não são idênticas, pois o que para o Poder Judiciário pode ser percebido como um ato delinquencial, para a clínica psicológica, por exemplo, pode ter outro diagnós-

36 CENTURIÃO, Luiz Ricardo Michaelsen. Alguns aspectos do menor de rua e seu contexto. In: GAUER, Gabriel José Chittó; GAUER, Ruth Maria Chittó (ORG.). A femenologia da violência. Curitiba: Juruá, 1999. p. 72.

37 TRINDADE, Jorge. Delinquência juvenil: uma abordagem transdisciplinar. 2 ed. Porto Alegre: Livraria do Advogado, 1996. p. 38. 
tico $^{38}$. Foucault afirma que o destaque à delinquência altera o cenário de como se vê a marginalidade e a vulnerabilidade, pois o delinquente é caracterizado pela vida que leva e dentro do sistema deve ser transformado pelo trabalho e pela individualização. Os efeitos da delinquência não ficam restritos ao delinquente e alcança sua família de maneira nefasta e patologizada ${ }^{39}$. Nenhuma ciência ou área de conhecimento é capaz de lidar isoladamente com todos os aspectos que envolvem a criminalidade juvenil e os fatores de risco e vulnerabilidade.

O estudo qualificado do comportamento dos jovens em situação de risco social só pode ser feito se integrados e compreendidos os conhecimentos advindos das diversas ciências e áreas de conhecimento. Além disso, a heterogeneidade das pessoas, junto com a particularidade de suas historicidades, impossibilita o estudo de forma única para todos. As vivências pessoais e a forma como cada ser humano lida com elas conferelhes uma individualização não apenas física ou biológica, mas também sociológica. Nesse sentido, Abreu entende que:

$\mathrm{Na}$ etiologia do crime, revelou-se insuficiente e contestável, a antiga e simplista opção de serem determinantes, ou preponderantes, os fatores biológicos, ou os sociológicos. Estes fatores atuam com intensidades diversas em cada sociedade e também diferentes na delinquência infanto-juvenil, em comparação com a criminalidade geral. As causas sociológicas têm mais peso nos países em desenvolvimento, vencendo inibições ao crime de indivíduos, que não cederiam a pressões mais atenuadas..$^{40}$

Não há maiores discordâncias quanto ao fato de que a manutenção biológica, emocional e social da criança e do adolescente traz importante contribuição para o desenvolvimento de sua personalidade e de seu caráter, mas a questão fundamental, e também a mais complexa de se

38 ALVES, Sirlei Fátima Tavares. Efeitos da internação sobre a psicodinâmica de adolescentes autores de ato infracional. São Paulo: Método, 2005. p. 45.

39 FOUCAULT, Michel. Vigiar e Punir: nascimento da prisão.Tradução de Raquel Ramalhete. Petrópolis: Vozes, 2005.

40 ABREU, Waldir de. A corrupção penal infanto-juvenil. Rio de Janeiro: Forense, 1995. p. 02. 
entender, é a partir de que ponto, perturbações em tais funções podem levar crianças e adolescentes a ingressarem no âmbito da infração ou da criminalidade juvenil.

Alves, ao estudar os múltiplos fatores de vulnerabilidade relacionados à delinquência juvenil, explica que "(...) a causa da delinquência pode ser multifocal, com elementos componentes de diversos fatores: socioeconômico, político familiar e individual. Esses fatores relacionamse dialeticamente e de forma diferenciada em cada indivíduo". ${ }^{41}$

Bordin e Offord ${ }^{42}$ relatam que existem comportamentos, como por exemplo, mentir e "matar" aula, que podem ser observados no curso do desenvolvimento normal de crianças e adolescentes. Segundo os autores, para diferenciar normalidade de psicopatologia, é importante verificar se estes comportamentos ocorrem esporadicamente e de modo isolado ou se constituem síndromes, representando um desvio do padrão de comportamento esperado para pessoas da mesma idade e sexo em determinada cultura (tempo e espaço coincidentes).

Ainda quanto às peculiaridades dos indivíduos e os vários aspectos que envolvem os fatores de ensejo à criminalidade, $\mathrm{Abreu}^{43}$ afirma que“(...) o argumento, mutatis mutandis, também serve às teorias psicogênicas, porque pessoas vivendo nas mesmas circunstâncias sociais, nem todas são criminosas. Não se impregnam e identificam da mesma forma. Sem nenhuma hesitação, mais uma vez acentue-se que são múltiplos os fatores conducentes ao crime".

Há muito se sabe que a criminalidade não faz parte apenas da vida das classes ditas desfavorecidas; embora muitos tenham dificuldades em admitir, nos dias de hoje não são apenas as classes pobres que veem seus filhos migrarem para o mundo do crime. Os filhos das classes A e B também integram esse fenômeno, o que nos leva a pensar em uma glamourização da criminalidade.

\footnotetext{
41 ALVES, Sirlei Fátima Tavares. Efeitos da internação sobre a psicodinâmica de adolescentes autores de ato infracional. São Paulo: Método, 2005. p. 47.

${ }^{42}$ BORDIN, Isabel A.S.; OFFORD, David R. Transtorno de conduta e comportamento anti-social.Revista Brasileira de Psiquiatria. Vol. 22 s.2 São Paulo. Dec. 2000. Disponível em: $<$ http://www.scielo.br/scielo.php?script=sci_arttext\&pid=S151644462000000600004>. Acesso em: 20 ago. 2008

43 ABREU, Waldir de. A corrupção penal infanto-juvenil. Rio de Janeiro: Forense, 1995. p. 06.
} 
Conforme já se apontou, apesar de a criminalidade juvenil estar inserida no imaginário social como um atributo específico das camadas mais pobres, sabe-se que ela não é uma derivação restritiva da pobreza. A compreensão da violência ou delinquência deve ser obtida a partir da análise dos diversos fatores que envolvem a questão. No caso dos adolescentes em situação de vulnerabilidade e risco social, a discussão envolve estigmas e estereótipos antigos, mas não superados pela sociedade. A imensa diferença social que abarca nosso país contribui para que as classes mais pobres se tornem alvo da rotulação de comportamentos violentos e delinquenciais.

A situação de risco passa a ser uma condição da criança e do adolescente que convive com uma realidade de adversidades, seja por problemas econômicos, sociais, familiares ou psicológicos.Nesse quadro de risco, o que mais chama atenção para os jovens é a omissão ou negligência, seja por parte dos pais e tutores, seja por parte do Estado e também da sociedade como um todo.

Esses meninos e meninas têm seus direitos fundamentais suprimidos diariamente, tais como o direito à saúde, à alimentação, à educação, à cultura, ao lazer, à liberdade, à dignidade e ao respeito. Além da mitigação de tais direitos, esses jovens muitas vezes sofrem por carência e abandono por parte daqueles que deveriam zelar pelo seu bem-estar. Fatores como gravidez precoce e indesejada, fome, alcoolismo, violência física e psicológica, exploração e abuso sexual, trabalho pesado, dependência e tráfico de drogas, são apenas alguns dos problemas que se encontram constantemente presentes na vida de muitos adolescentes em situação de risco.

Os fatores de risco aqui abordados e suas consequências na vida dos jovens podem ser vislumbrados em maior ou menor escala. Farrington $^{44}$, em obra publicada pela UNESCO, explica que os fatores de risco podem ser entendidos como variáveis que desencadeiam um alto índice de violência juvenil, tais como a mera impulsividade, o baixo desempenho escolar, pais criminosos, baixa renda familiar e a supervisão parental deficiente.

Estes fatores de risco não são encontrados de forma única e exclusiva nas classes desfavorecidas, pois conforme já dito, famílias da

\footnotetext{
${ }^{44}$ FARRINGTON, David P. Fatores de risco para a violência juvenil. In: DEBARBIEUX, Eric; BLAYA, Catherine (Org.) Violência nas escolas e políticas públicas. Brasília: UNESCO, 2002. p. 25.
} 
classe média e alta também apresentam tais fatores. O que muda é a visibilidade social e o acesso a meios de compreensão da revolta juvenil, o que nem sempre é possível quando se trata de grupos mais vulneráveis. Neste sentido, é interessante a reflexão de Abramovay, ao afirmar que:

Outro aspecto perverso da vulnerabilidade é a escassa disponibilidade de recursos materiais ou simbólicos a indivíduos ou grupos excluídos da sociedade. $\mathrm{O}$ não acesso a determinados insumos (educação, trabalho, saúde, lazer e cultura) diminui as chances de aquisição e aperfeiçoamento desses recursos que são fundamentais para que os jovens aproveitem as oportunidades oferecidas pelo Estado, mercado e sociedade para ascender socialmente..$^{45}$

Cabe salientar que a vulnerabilidade, ou a própria exclusão social por si só, não impede a aderência da criança e do adolescente a normas ou padrão de condutas socialmente estabelecidas. Exemplo dessa questão encontra-se no comportamento de meninos e meninas de rua, que desenvolvem uma expressividade própria, sentindo-se iguais aos que compartilham as suas vivências, e da mesma forma se percebem diferentes daqueles que vivem em realidades opostas àquelas em que vivem. A partir disso, o menino de rua vai construindo a sua autoimagem, baseada no relacionamento que ele tem com os demais. E apesar de tais meninos não terem comportamentos tidos como aceitáveis pelo restante da sociedade, isso não quer dizer que eles não tenham um código de conduta. Aliás, o sentimento de estar à margem, de fazer parte de um grupo diferenciado, de sentir-se diferente dos demais que compõe a sociedade, sendo encarados como "desviantes", faz com que esses meninos desenvolvam códigos restritos e específicos a seu grupo, que opera como grupo de "oposição" à sociedade abrangente. ${ }^{46}$

Tal sentimento é similar àquele que envolve os jovens em situação de risco social, uma vez que muitos jovens são motivados em suas

\footnotetext{
${ }^{45}$ ABRAMOVAY, Miriam. Juventude, violência e vulnerabilidade social na América Latina: desafios para políticas públicas. Miriam Abramovayet alii. Brasília: UNESCO, BID, 2002. p. 33.

46 CENTURIÃO, Luiz Ricardo Michaelsen. Alguns aspectos do menor de rua e seu contexto. In: GAUER, Gabriel José Chittó; GAUER, Ruth Maria Chittó (ORG.). A femenologia da violência. Curitiba: Juruá, 1999. p. 68.
} 
condutas pela procura de bem-estar e compreensão e se identificam com aqueles que possuem uma realidade próxima a deles, ou que parecem lhe entender, distanciando-se daqueles com os quais não possuem tanta familiaridade.

\section{FORMAS DE VIOLÊNCIA ASSOCIADAS ÀS CRIANÇAS E AOS ADOLESCENTES}

A violência nos dias atuais toma contornos diversos e incorpora inúmeras formas e variáveis. Neste sentido, importante é a compreensão dos fenômenos da violência difusa, que passam a disseminar-se por toda a sociedade. Trata-se de uma multiplicidade de formas de violência presentes nas sociedades contemporâneas, tais como a violência ecológica, a exclusão social, a violência entre os gêneros, racismos, violência na escola, entre outras, configurando-se em um dilaceramento da cidadania. ${ }^{47}$

Dentro do fenômeno da violência difusa, insere-se também a violência intrafamiliar, que não é um fenômeno novo, mas que aterroriza e amedronta diversas crianças e adolescentes, deixando reflexos e consequências para toda vida.

Segundo conceituação do Ministério da Saúde ${ }^{48}$ a violência intrafamiliar é toda ação ou omissão que acarrete em prejuízos para o bemestar, para a integridade física, psicológica ou à liberdade e o direito ao pleno desenvolvimento de algum outro membro da família, podendo ser cometida dentro ou fora de casa por quem faz parte da família, o que abarca inclusive pessoas que passam a assumir a função parental, mesmo que sem laços de consanguinidade, e em relação de poder à outra.

Essa espécie de violência pode se desenvolver de diversas formas, seja através da violência física, do abuso sexual, do trabalho doméstico infantil, ou da violência moral e psicológica.

Dados da Organização Mundial de Saúde (OMS), publicados no Relatório do Dia Mundial da Saúde Mental, pela WorldFederation for

\footnotetext{
47 SANTOS, José Vicente Tavares dos. Violências e conflitualidades. Porto Alegre: Tomo Editorial, 2009. p. 143.

48 BRASIL. Ministério da Saúde. Secretaria de Políticas da Saúde. Violência intrafamiliar: orientações para a prática em serviço. Brasília: Ministério da Saúde, 2001. p. 15.
} 
Infant Mental Health (WHOM) ${ }^{49}$, apontam que cerca de 40 mil crianças com idade abaixo de 15 anos são vítimas todos os anos de várias formas de violência e privação, sendo que segundo a UNICEF, entre 1985 e 1995, mais de 2 milhões de crianças foram massacradas, 6 milhões foram gravemente feridas, e 12 milhões ficaram sem abrigo.

As diversas formas de violência sofridas por crianças e adolescentes são cumulativas e não excludentes entre si, pois a violência sexual, por exemplo, é também violência física e psicológica; a violência física é sempre também psicológica. Por exemplo, na exploração sexual comercial, também se encontram presentes, além da exploração econômica, as violências estrutural, física, psicológica e moral. Também, a violência simbólica estimula todas as outras formas de violência. ${ }^{50}$

A violência física é a mais visível e ocorre quando alguém que está em posição de poder em relação à outra lhe causa ou tenta causar dano não acidental, por meio do uso da força física ou do emprego de algum tipo de armas que pode ou não provocar lesões externas, internas ou ambas. Segundo as concepções mais recentes, o castigo repetido, não severo, também se considera violência física. Essa violência pode ser manifestada de diversas formas, incluindo tapas, empurrões, socos, mordidas, chutes, queimaduras, cortes, estrangulamento, lesões por armas e objetos, a ingestão obrigatória de medicamentos desnecessários ou inadequados, bem como álcool, drogas e outras substâncias, e danos à integridade corporal e negligência (omissão de cuidados e falta de proteção contra agravos evitáveis, como situações de perigo, doenças, gravidez, alimentação, higiene), etc. ${ }^{51}$

Além da violência física, a violência psicológica é constante em grande parte dos lares. Essa forma de violência pode se desenvolver de diversas maneiras e pode consistir tanto em agressões verbais quanto

49 WORLD FEDERATION FOR INFANT MENTAL HEALTH (WHOM), 2002.Relatório do Dia Mundial da Saúde Mental, 2002.

${ }^{50}$ FALEIROS, Vicente de Paula; FALEIROS, Eva Silveira. A violência sexual contra crianças e adolescentes e a construção de indicadores: a crítica do poder, da desigualdade e do imaginário. In: LEAL, Maria de Fátima Pinto; CÉSAR, Maria Auxiliadora (Org.) Indicadores de violência intra-familiar e exploração sexual comercial de crianças e adolescentes. Brasília: CECRIA - Centro de Referência, Estudos e Ações sobre Crianças e Adolescentes, 1998. p. 31.

51 BRASIL. Ministério da Saúde. Secretaria de Políticas da Saúde. Violência intrafamiliar: orientações para a prática em serviço. Brasília: Ministério da Saúde, 2001. p. 18. 
gestuais, no intuito de amedrontar e aterrorizar as vítimas, humilhando-as, excluindo-as, limitando sua liberdade, ou isolando-as do convívio social, ou ainda, fazendo com que elas próprias se isolem. No caso de crianças e adolescentes, principalmente por esses estarem em fase de intenso processo de desenvolvimento, o sofrimento derivado dessa forma de violência traz prejuízos severos para sua formação.

O acometimento da violência psicológica traz também consequências diretas à autoestima, autorrespeito e autoconfiança dos jovens, dificultando seu relacionamento com os demais. Neste sentido, Assis e Avanci afirmam que:

Alunos com autoestima mais depreciativa se sentem: mais humilhados e diminuídos pelos adultos que dizem que eles não são bons, que os chamam de nomes desagradáveis ou que fazem piadas sobre eles; mais culpados pelas falhas cometidas pelos outros; mais criticados pela aparência, pelos amigos que possuem, pelas coisas que fizeram ou disseram e por adultos que reforçaram que estavam errados; mais cobrados pelos adultos, sendo forçados a assumirem muitas tarefas domésticas; mais desvalorizados pelos adultos que não demonstraram interesse por eles, ignorando-os quando precisavam de carinho; deixando de elogiá-los quando agiram corretamente, não estimulando-os para os desafios, gritando com eles sem motivos e não acreditando neles. ${ }^{52}$

Outra preocupante forma de violência presente em muitas famílias brasileiras é a violência intrafamiliar sexual contra crianças e adolescentes. Essa forma de violência é devastadora e deixa marcas visíveis e invisíveis, o que agrava ainda mais a situação de suas vítimas, uma vez que grande maioria sofre calada com os efeitos da violência psicológica trazidos pelo abuso sexual. Corroborando com tal assertiva, os estudos de Zimerman apontam que:

52 ASSIS, Simone Gonçalves de; AVANCI, JovianaQuintes. Abuso psicológico e desenvolvimento infantil. In: Violência faz mal à saúde. Cláudia Araújo de Lima (Coord.) et al. Brasília: Ministério da Saúde, 2006. p. 63. 
Diferentemente das agressões físicas que deixam marcas (hematomas, fraturas de ossos, queimaduras), mesmo quando este tipo de violência contra a criança não deixa pistas visíveis (em casos de pedofilia, por exemplo), as marcas do abuso ficam impressas no psiquismo da criança sob a forma de sérios "traumas" que podem acompanhá-la por toda a vida, com consideráveis prejuízos no comportamento do futuro adulto. ${ }^{53}$

Quanto à violência intrafamiliar merece atenção, também, a violência sofrida dentro de casa por irmãos, sendo comum a existência de xingamentos, humilhações e agressões físicas entre eles, e apesar de aceita socialmente, essa violência pode sinalizar o tipo de relacionamento que a criança ou o adolescente tem dentro e fora de casa $^{54}$, permitindo a reprodução desse comportamento de forma indiscriminada.

Como se vê, a violência intrafamiliar reflete consequências em toda a família, fortalecida também pelas questões de gênero, pois conforme aponta Leal:

Em função da desordem familiar provocada pela violência masculina emerge na família um conjunto de práticas violentas com novos atores, isto é, o pai/padrasto, que desencadeou o processo, agora não é o único a cometer atos de violência, mas outros elementos da família, exemplo: mãe, filhos e outros, criando-se um clima de violência. ${ }^{55}$

${ }^{53}$ ZIMERMAN, David. Os quatro vínculos: amor, ódio, conhecimento reconhecimento na psicanálise e em nossas vidas. Porto Alegre: Artmed, 2010. p. 130.

54 BRASIL Secretaria de Atenção à Saúde. Departamento de Ações Programáticas Estratégicas. Linha de cuidado para a atenção integral à saúde de crianças, adolescentes e suas famílias em situação de violências: orientação para gestores e profissionais da saúde. Brasília: Ministério da Saúde, 2010. p. 29.

${ }^{55}$ LEAL, Maria Lúcia Pinto. Violência intra-familiar: um estudo preliminar. In: LEAL, Maria de Fátima Pinto; CÉSAR, Maria Auxiliadora (Org.) Indicadores de violência intra-familiar e exploração sexual comercial de crianças e adolescentes. Brasília: CECRIA - Centro de Referência, Estudos e Ações sobre Crianças e Adolescentes, 1998. p. 19. 
Além de todas essas formas de violência contra crianças e adolescentes pela ação de adultos ou de seus pares (irmãos, amigos, colegas, etc.), a omissão também deve ser encarada como uma forma de violência quando compromete o dever/ poder de proteger do adulto e coisifica a infância/juventude pela negação do reconhecimento aos sujeitos e pessoas em situação peculiar de desenvolvimento. ${ }^{56}$

A violência chamada de "institucional", insere-se também nesse contexto e é resultante da precariedade de acesso aos serviços necessários a quem foi vítima da violência intrafamiliar. A violência institucional abrange a falta de qualidade ou inadequação do atendimento e se constitui em mais uma forma de violência a quem busca apoio após sofrer violência. É um paradoxo na medida em que a pessoa violentada sofre novamente violência quando busca ajuda junto ao Poder Estatal. Nesse sentido, conforme apontam Souza e Jorge:

Violência intrafamiliar e institucional são formas agressivas e cruéis de se relacionar no interior das famílias, na escola e em instituições como albergues e internatos, produzindo danos físicos, emocionais, sexuais e, por vezes, até a morte. A violência intrafamiliar e a violência institucional são produzidas frequentemente tendo como justificativa educar e corrigir erros de comportamento de crianças e adolescentes. As violências social, intrafamiliar e institucional se expressam sob diferenciadas formas e, quando relacionadas às crianças e adolescentes, costumam ser classificadas como negligência, abuso físico, abuso sexual e abuso psicológico. ${ }^{57}$

Essa violência abrange abusos cometidos em virtude das relações de poder desiguais entre usuários e profissionais dentro das instituições, e pode ser identificada de diversas formas, tais como: a peregrinação por diversos serviços até receber atendimento; falta de escuta ade-

56 TRINDADE, Jorge. Delinquência juvenil: uma abordagem transdisciplinar. 2 ed. Porto Alegre: Livraria do Advogado, 1996. p. 246.

57 SOUZA, Edinilsa Ramos de; JORGE, Maria Helena Prado de Mello. Impacto da violência na infância e adolescência brasileiras: magnitude da morbimortabilidade. In: Violência faz mal à saúde. Cláudia Araújo de Lima (Coord.) et al. Brasília: Ministério da Saúde, 2006. p. 24. 
quada e tempo dos técnicos para atender as vítimas; frieza, rispidez, falta de atenção, negligência; maus tratos dos profissionais para com usuários dos serviços, motivados por discriminações, abrangendo questões de raça, idade, opção sexual, gênero, deficiência física, doença mental; violação dos direitos reprodutivos, incluindo a discriminação das mulheres em processo de abortamento, aceleração do parto para liberar leitos, preconceitos acerca dos papéis sexuais, e em relação às mulheres soropositivas (HIV), quando estão grávidas ou desejam engravidar; desqualificação do saber prático, da experiência de vida, diante do saber científico; a violência física (por exemplo, a negativa de acesso à anestesia como forma de punição, uso de medicamentos para adequação do paciente às necessidades do serviço ou do profissional, etc.); detrimento das necessidades e direitos da clientela; proibições de acompanhantes ou visitas; críticas ou agressões a quem grita ou expressa dor e desespero, ao invés de tentar acalmar o paciente; e diagnósticos imprecisos, acompanhados de prescrições de medicamentos inadequados. ${ }^{58}$

De fato, o despreparo das instituições para lidar com a questão da violência intrafamiliar acaba afetando de forma ainda mais negativa a vida das vítimas que decidem denunciar seus agressores ou necessitam de atendimento especializado.

A questão merece atenção de quem se dedica a trabalhar com políticas públicas e programas de inserção social de adolescentes em situação de risco social, uma vez que a violência intrafamiliar é parte integrante dessa situação de risco, principalmente quando a vítima é o jovem pois que os reflexos futuros podem ser negativos, incluindo a própria dificuldade em sua inclusão e manutenção dentro dos programas de apoio, influenciando nos sentimentos de pertencimento, reconhecimento e vínculos que serão ou não estabelecidos dentro desses projetos.

\section{REFLEXOS DO MEDO E DA INSEGURANÇA NA SOCIEDADE DO RISCO E NO COTIDIANO DOS JOVENS}

\footnotetext{
58 BRASIL. Ministério da Saúde. Secretaria de Políticas da Saúde. Violência intrafamiliar: orientações para a prática em serviço. Brasília: Ministério da Saúde, 2001. p. 21-22.
} 
$\mathrm{Na}$ realidade permeada por riscos e inseguranças o sentimento de medo é crescente e toma conta da sociedade. Esse sentimento se reflete tanto nos discursos e atitudes dos adultos em geral, quanto nos discursos e atitudes dos jovens em situação de risco social.

Conforme aponta Beck:

Hoje em dia, os mundos social e natural estão totalmente influenciados pelo conhecimento humano reflexivo; mas isso não conduz a uma situação que nos permita ser, coletivamente, os donos do nosso destino. Muito ao contrário: o futuro se parece cada vez menos com o passado e, em alguns aspectos básicos, tem se tornado muito ameaçador. Com espécie, não temos mais uma sobrevivência garantida, mesmo a curto prazo - isto é uma consequência de nossos próprios atos, como coletividade humana. Hoje em dia, a noção de "risco" é fundamental para a cultura moderna justamente porque grande parte do nosso pensamento tem de ser do tipo "como se". Em muitos aspectos de nossas vidas, tanto individual quanto coletiva, temos de construir regularmente futuros potenciais, sabendo que essa mesma construção pode, na verdade, impedir que eles venham a acontecer. Novas áreas de imprevisibilidade são muito frequentemente criadas pelas próprias tentativas que buscam controlá-las. ${ }^{59}$

Nos dias atuais, qualquer projeção para o futuro tem de ser obrigatoriamente relativizada, pois, por mais que se planeje algo, sabe-se que a realização de um ato qualquer pode desencadear diversas mudanças na realidade habitual. Se planejar o futuro é tarefa complicada para a maioria dos adultos, para os jovens em situação de risco social tal tarefa se mostra infinitamente mais complexa. Como vimos, por si só a adolescência já é uma fase extremamente turbulenta que desencadeia em atos por vezes imprevisíveis. Pelo quadro de risco social, a adolescência se

\footnotetext{
59 BECK, Ulrich; GIDDENS, Anthony; LASCH, Scott. Modernização reflexiva: política, tradição e estética na ordem social moderna. Tradução de Magda Lopes. São Paulo: Universidade Estadual Paulista, 1997. p. 9.
} 
complexifica em termos de planejamento futuro, principalmente quando a incerteza faz parte das condições, tanto físicas, quanto econômicas, afetivas ou familiares, para realizar os planos.

Sobre esse universo de transformações, e incertezas Giddens traz importante reflexão ao afirmar que:

Entre todas as mudanças que estão se dando no mundo, nenhuma é mais importante do que aquelas que acontecem em nossas vidas pessoais - na sexualidade, nos relacionamentos, no casamento e na família. Há uma revolução global em curso no modo como pensamos sobre nós mesmos e no modo como formamos laços e ligações com outros. É uma revolução que avança de maneira desigual em diferentes regiões e culturas, encontrando muitas resistências. ${ }^{60}$

O fato é que a sociedade atual têm sofrido inúmeras mudanças em seus mais variados contextos; os próprios planos dos jovens de hoje são infinitamente distintos dos planos que seus pais tinham na sua idade e o mais impressionante é que tais mudanças são constantes, não tendo nenhuma previsibilidade quanto a seu começo ou forma de realização.

Tavares dos Santos $^{61}$ aponta diversas mudanças provocadas nas instituições, tais como a família, a escola, os processos de socialização, as fábricas, as religiões, e principalmente no sistema de justiça criminal, que vive um processo de crise e desinstitucionalização. Conforme o autor, a crise da família cristaliza tais mudanças nos laços sociais, uma vez que as funções sociais dessa unidade social marcada por relações de parentesco estão atualmente ameaçadas, em decorrência de mais de um fator:

Por um lado, em decorrência da própria diversidade de tipos de família no Brasil atual - família nuclear, família extensa em algumas áreas rurais e urbanas, famílias monoparentais, famílias por agregação, Por

${ }^{60}$ GIDDENS, Anthony. Mundo em descontrole. Tradução de Maria Luiza X. de A. Borges. Rio de Janeiro: Record, 2000. p. 61.

61 SANTOS, José Vicente Tavares dos. Violências e conflitualidades. Porto Alegre: Tomo Editorial, 2009. p. 19. 
outro, os tipos de relações de sociabilidade que nela se realizam são variados: marcadas originalmente pela afetividade e pela solidariedade, agora as relações reaparecem como largamente conflitivas, como o demonstram os fenômenos da violência doméstica. As funções de sociabilização passam a ser compartilhadas pela escola e pelos meios de comunicação. Identifica-se uma desorganização do grupo familiar, com as funções de reprodução econômica ameaçadas pela crise do emprego assim como pelos efeitos da crise do Estado-Providência. ${ }^{62}$

Por sua vez, Beck, ao relatar essa dinâmica de transformação que destrói e modifica o outro, nominada de "modernização reflexiva", afirma que:

(...) em virtude de seu inerente dinamismo, a sociedade moderna está acabando com suas formações de classe, camadas sociais, ocupação, papéis dos sexos, família nuclear, agricultura, setores empresariais e, é claro, também com os prérequisitos e as formas contínuas do progresso técnico-econômico. Esse novo estágio, em que o progresso pode se transformar em autodestruição, em que um tipo de modernização destrói o outro e o modifica, é o que eu chamo de etapa da modernização reflexiva. ${ }^{63}$

Seguindo tal reflexão, Beck ${ }^{64}$ afirma que o conceito de sociedade de risco "designa uma fase no desenvolvimento da sociedade moderna, em que os riscos sociais, políticos, econômicos e individuais tendem cada vez mais a escapar das instituições para o controle e a proteção da sociedade individual”.

\footnotetext{
62 SANTOS, José Vicente Tavares dos. Violências e conflitualidades. Porto Alegre: Tomo Editorial, 2009. p. 19.

${ }^{63}$ BECK, Ulrich; GIDDENS, Anthony; LASCH, Scott.Modernização reflexiva: política, tradição e estética na ordem social moderna. Tradução de Magda Lopes. São Paulo: Universidade Estadual Paulista, 1997. p. 12.

${ }^{64}$ Idem. p. 15-16.
} 
O crescimento da sensação de medo e insegurança coletiva com reflexos em praticamente todas as esferas sociais faz parte do cenário atual e mobiliza discursos sobre a suposta necessidade de enrijecimento das punições penais, como se essas pudessem afastar ainda que momentaneamente todos os riscos trazidos pelas diversas formas de violências.

A criminalidade está presente na vida de todos e, aceitando ou não, figuramos nesse contexto, se não como personagens de tais atos, como espectadores temerários da realidade que estamos a viver. Como afirma Abramovay:

Devido à generalização do fenômeno da violência não existem mais grupos sociais protegidos, diferentemente de outros momentos, ainda que alguns tenham mais condições de buscar proteção institucional e individual. Isto é, a violência não mais se restringe a determinados nichos sociais, raciais, econômicos e/ou geográficos, entretanto, como se pretende demonstrar, considerando-se modalidades de violência, ela pode se acentuar por gênero, idade, etnia e classe social, independentemente se como vítimas ou como agentes. ${ }^{65}$

Nesse sentido, também Muñoz Conde ${ }^{66}$ afirma que "a violência está aí à vista de todos e praticada por todos: pelos que delinquem e pelos que definem e sancionam a delinquência, pelo indivíduo e pelo Estado, pelos pobres e pelos ricos", o que de fato amedronta a todos e incrementa o discurso pela maior repressão penal, bem como a taxatividade de diversos tipos de condutas como delinquenciais.

Tavares dos Santos afirma que "na vida cotidiana, realiza-se uma inter-relação entre mal-estar, violência simbólica e sentimento de insegurança" ${ }^{67}$, e prossegue:

${ }^{65}$ ABRAMOVAY, Miriam. Juventude, violência e vulnerabilidade social na América Latina: desafios para políticas públicas. Miriam Abramovayet alii. Brasília: UNESCO, BID, 2002. p. 13.

${ }^{66}$ CONDE, Francisco Muñoz. Direito penal e controle social. Tradução de Cíntia Toledo Miranda Chaves. Rio de Janeiro: Forense, 2005. p. 04.

67 SANTOS, José Vicente Tavares dos. Violências e conflitualidades. Porto Alegre: Tomo Editorial, 2009. p. 32. 
Trata-se de uma ruptura do contrato social e dos laços sociais, provocando fenômenos de desfiliação e de ruptura nas relações de alteridade, dilacerando o vínculo entre o eu e o outro. Tais rupturas verificamse nas instituições socializadoras - famílias, escolas, fábricas, religiões - e no sistema de justiça penal polícias, academias de polícia, tribunais manicômios judiciários, instituições da justiça penal e prisões pois todas vivem um processo de ineficácia do controle social e passam a uma fase de desinstitucionalização ou de recorrente crise. ${ }^{68}$

A proliferação da sensação de medo como controle e/ou respeito é almejada e buscada pelos grupos criminosos para que consigam, através das ameaças, impor suas vontades ou se fazer respeitar. Barreira traz o exemplo em que:

O terror, gerado no Estado de São Paulo e, com menores repercussões, em outros estados, é implantado mediante ataques, tendo como alvo principal os postos policiais, viaturas e bares frequentados por policiais, como também rebeliões realizadas no interior dos presídios. Os alvos são calculados politicamente para fragilizar os órgãos de segurança pública e não atingir indiscriminadamente a população. Estas ações ousadas, super-organizadas e poderosas, têm como meta desafiar abertamente o Estado e seu monopólio do uso da violência; um monopólio que dificulta cada vez mais os estados de assumirem sua função clássica. O monopólio legítimo da violência física parece mais atomizado e cada vez menos adaptado às realidades contemporâneas. ${ }^{69}$

68 SANTOS, José Vicente Tavares dos. Violências e conflitualidades. Porto Alegre: Tomo Editorial, 2009. p. 33.

69 BARREIRA, Cézar. Cotidiano despedaçado - cenas de uma violência difusa. Fortaleza, CE: Universidade Federal do Ceará/Funcap/CNPq-Pronex; Campinas, SP: Pontes, 2008. p. 239. 
As sensações de medo e de insegurança produzem reflexos no comportamento das pessoas que buscam se proteger desses temores. Quanto maior é a exposição à violência, e quanto mais grave esta se revela, maior é seu impacto sobre o comportamento dos indivíduos, produzindo uma generalização do medo que passa a afetar o modo como as pessoas usam a cidade, incluindo as ruas do bairro onde vivem, quer seja dia ou noite. ${ }^{70}$

Toda essa realidade, onde o medo de se tornar vítima é constante, faz aumentar o discurso por penas mais rígidas. Esse discurso equaliza as condutas como se elas se desenvolvessem de forma única e atroz e devessem ser combatidas unicamente através da repressão penal. Isso acaba por aumentar o poder dos grupos criminosos que aproveitam o terror e com suas ações aumentam a sensação de medo e insegurança à coletividade, numa espiral de poder que se alimenta justamente da disseminação e fortalecimento de tais sensações. Além disso, os clamores públicos por maior repressão voltam-se na maioria dos casos em desfavor das pessoas mais vulneráveis à violência, renegando-se as demais formas de controle social diferentes da repressão penal, sem contar que os crimes de colarinho e aqueles praticados pelas organizações criminosas são punidos minimamente, o que excluído circuito penal os grandes grupos criminosos que não compõem a população vulnerável.

$\mathrm{O}$ raciocínio de Bauman, ao se referir à política de lei e ordem voltada à punição da criminalidade de rua praticada pelos imigrantes, potenciais gatunos e batedores de carteira, pode ser aplicado analogamenteao Brasil no tocante à criminalidade juvenil, onde ela é vista como se não ultrapassasse as barreiras de uma derivação restritiva da pobreza e dos grupos vulneráveis. Nesse sentido, interessante são as palavras do autor quando afirma que:

$\mathrm{Na}$ maior parte do tempo, a maioria dos poderes políticos não tem capacidade nem disposição para se engajar na luta contra as forças criminosas que, com frequência demasiada, controlam recursos que

\footnotetext{
70 CARDIA, Nancy. Exposição à violência: seus efeitos sobre valores e crenças em relação à violência, polícia e direitos humanos. In: Violenceset controle de laviolenceauBresil, em Afrique et a Goa. Lusotopie, 2003. pp. 299-328. Disponível em: http://www.lusotopie.sciencespobordeaux.fr/somma2003.html. Acesso em: 6 de nov. de 2011. p. 316.
} 
nenhum governo, sozinho e muitas vezes em conjunto, pode igualar. Essa é uma das razões pelas quais, na visão de Bernard, os governos preferem dirigir a animosidade popular contra os pequenos crimes a se engajar em batalhas que com toda probabilidade prosseguirão por um tempo interminável e decerto consumirão recursos incalculáveis, mas que tendem virtualmente a serem perdidas. Procurar o Inimigo Público Número 1 entre os infelizes imigrantes dos banlieus e nos acampamentos para pessoas em busca de asilo é bem mais oportuno e conveniente, mas acima de tudo menos incômodo. Com maior efeito e menores custos, os bairros de imigrantes, repletos de potenciais gatunos e batedores de carteira, podem ser usados como campos de batalha na grande guerra pela lei e a ordem que os governos travam com muito vigor e publicidade ainda maior, embora não sejam avessos a "terceirizá-la" e sublocá-la a empresas de segurança privadas e a iniciativas da parte dos cidadãos. ${ }^{71}$

É justamente a disseminação da sensação de medo e de insegurança que acaba por fomentar ações e políticas de segurança pública ineficazes, baseadas unicamente na repressão restrita àqueles que podem cometer crimes, mas que também são vítimas diárias de todas as formas e tipos de violência. No entanto a possibilidade de vitimização desses grupos não é levada em consideração ou é ignorada na implementação de práticas de segurança pública e repressão penal.

\section{CONSIDERAÇÕES FINAIS}

A juventude constitui hoje uma categoria que convive diariamente com uma realidade permeada por medos e insegurança. De um lado seus componentes são propensas vítimas da violência; muitos vivenciam desde cedo todas as formas possíveis de afronta a seus direitos fun-

71 BAUMAN, Zymunt. Vidas desperdiçadas. Trad. Carlos Alberto Medeiros. Rio de Janeiro: Jorge Zahar, 2005. p. 82. 
damentais e se tornam vítimas dentro de suas próprias casas, por aqueles que deveriam lhes propiciar apoio e segurança aos seus direitos. De outro lado, é comum no discurso do senso comum o clamor por penas mais rígidas e redução da maioridade penal como se estas fossem soluções para todas as formas de violência e criminalidade.

A violência difusa se mostra como constante na sociedade e os fatores de vulnerabilidade e risco social não são "privilégios" das camadas mais pobres. As classes médias e altas também convivem com fatores de violência intra e extrafamiliar, às vezes até em maior escala. $\mathrm{O}$ que muda de uma realidade para outra é que,quando se descobre a violência nas classes mais altas, as vítimas dessa geralmente tem melhor acesso aos meios e aos profissionais habilitados para lidar com o impacto dessas violências, tais como psicólogos, terapeutas, pedagogos, etc., o que é raro nas camadas mais pobres.

De um lado os adolescentes são vistos como as maiores vítimas da violência, mas de outro lado podem ser os perpetradores. Essa realidade remete os jovens a uma constante sensação de medo e insegurança que afeta os seus planos para o futuro. Esses jovens possuem sonhos e desejos profissionais com os quais se identifiquem, porém, muitas vezes, acabam prendendo estes sonhos dentro de si mesmos em razão de um olhar da sociedade que comumente os instiga a abandonar sonhos mais audaciosos.

Como se sabe, a adolescência é uma fase extremamente turbulenta, tanto para o adolescente, quanto para seus pais, familiares e todos que participam dessa fase de socialização e construção de disposições que serão por eles incorporadas. É a fase das descobertas e da insegurança.

Os jovens das camadas mais pobres acabam por se conformar ou com atividades clandestinas, ligadas à criminalidade, ou com atividades encaradas como subalternas pelo restante da sociedade. Situação cômoda para os demais, uma vez que a realidade se reproduz, conservando as profissões de maior prestígio para os mais abastados.

Como reflexo dessa realidade, as políticas de segurança pública voltam seus olhares mais diretamente para a questão da repressão penal e quando tratam da questão social o fazem de forma despreparada, focando somente na prevenção à violência, aumentando os medos dos jovens em ultrapassar as barreiras já estabelecidas pela sociedade em termos de futuro e profissão. 


\section{REFERÊNCIAS BIBLIOGRÁFICAS}

ABRAMOVAY, Miriam. Juventude, violência e vulnerabilidade social na América Latina: desafios para políticas públicas. Miriam Abramovayet alii. Brasília: UNESCO, BID, 2002.

ABREU, Waldir de. A corrupção penal infanto-juvenil. Rio de Janeiro: Forense, 1995.

ALVES, Sirlei Fátima Tavares. Efeitos da internação sobre a psicodinâmica de adolescentes autores de ato infracional. São Paulo: Método, 2005.

ASSIS, Simone Gonçalves de; AVANCI, JovianaQuintes. Abuso psicológico e desenvolvimento infantil. In: Violência faz mal à saúde. Cláudia Araújo de Lima (Coord.) et al. Brasília: Ministério da Saúde, 2006.

BARREIRA, Cézar. Cotidiano despedaçado - cenas de uma violência difusa. Fortaleza, CE: Universidade Federal do Ceará/Funcap/CNPq-Pronex; Campinas, SP: Pontes, 2008.

BAUMAN, Zymunt. Vidas desperdiçadas. Tradução de Carlos Alberto Medeiros. Rio de Janeiro: Jorge Zahar, 2005.

BECK, Ulrich; GIDDENS, Anthony; LASCH, Scott.Modernização reflexiva: política, tradição e estética na ordem social moderna. Tradução de Magda Lopes. São Paulo: Universidade Estadual Paulista, 1997.

BORDIN, Isabel A.S.; OFFORD, David R. Transtorno de conduta e comportamento anti-social.Revista Brasileira de Psiquiatria. Vol. 22 s.2 São Paulo. Dec. 2000. Disponível em: $<$ http://www.scielo.br/scielo.php?script=sci_arttext\&pid=S151 6-44462000000600004>. Acesso em: 20 ago. 2008.

BRASIL. Estatuto da Criança e do Adolescente. Lei n. 8.069, de 90. Disponível em: <http://www.planalto.gov.br/ccivil_03 /leis/L8069.htm.> Acesso em: 27 de jan. de 2012.

- Secretaria de Atenção à Saúde. Departamento de Ações Programáticas Estratégicas. Linha de cuidado para a atenção integral à saúde de crianças, adolescentes e suas famílias em situação de violências: orientação para gestores e profissionais da saúde. Brasília: Ministério da Saúde, 2010.

BRASIL. Ministério da Saúde. Secretaria de Políticas da Saúde. Violência intrafamiliar: orientações para a prática em serviço. Brasília: Ministério da Saúde, 2001. 
CARDIA, Nancy. Exposição à violência: seus efeitos sobre valores e crenças em relação à violência, polícia e direitos humanos. In: Violenceset controle de laviolenceauBresil, em Afrique et a Goa. Lusotopie, 2003. Disponível em: http://www.lusotopi e.sciencespobordeaux.fr/somma2003.html. Acesso em: 6 de nov. de 2011.

CENTURIÃO, Luiz Ricardo Michaelsen. Alguns aspectos do menor de rua e seu contexto. In: GAUER, Gabriel José Chittó; GAUER, Ruth Maria Chittó (ORG.). A femenologia da violência. Curitiba: Juruá, 1999.

CONDE, Francisco Muñoz. Direito penal e controle social. Tradução de Cíntia Toledo Miranda Chaves. Rio de Janeiro: Forense, 2005.

FALEIROS, Vicente de Paula; FALEIROS, Eva Silveira. Escola que protege: enfrentando a violência contra crianças e adolescentes. 2. ed. Brasília: Ministério da Educação, Secretaria da Educação Continuada, Alfabetização e Diversidade. 2008.

; A violência sexual contra crianças e adolescentes e a construção de indicadores: a crítica do poder, da desigualdade e do imaginário. In: LEAL, Maria de Fátima Pinto; CÉSAR, Maria Auxiliadora (Org.) Indicadores de violência intra-familiar e exploração sexual comercial de crianças e adolescentes. Brasília: CECRIA - Centro de Referência, Estudos e Ações sobre Crianças e Adolescentes, 1998.

FARRINGTON, David P. Fatores de risco para a violência juvenil. In: DEBARBIEUX, Eric; BLAYA, Catherine (Org.) Violência nas escolas e políticas públicas. Brasília: UNESCO, 2002.

FONSECA, Dirce Mendes da.O discurso de proteção e as políticas públicas sociais para infância e juventude.Revista Jurídica, Brasília, v.9, n.85, p. 73-82, jun./jul.2007.

FOUCAULT, Michel. Vigiar e Punir: nascimento da prisão.Tradução de Raquel Ramalhete. Petrópolis: Vozes, 2005.

GIDDENS, Anthony. Mundo em descontrole. Tradução de Maria Luiza X. de A. Borges. Rio de Janeiro: Record, 2000.

KLOSINSKI, Gunther. A adolescência hoje: situações, conflitos e desafios. Tradução de Carlos Almeida Pereira. Petrópolis: Vozes, 2006.

LEAL, Maria Lúcia Pinto. Violência intra-familiar: um estudo preliminar. In: LEAL, Maria de Fátima Pinto; CÉSAR, Maria Auxiliadora (Org.) Indicadores de violência intra-familiar e exploração 
sexual comercial de crianças e adolescentes. Brasília: CECRIA Centro de Referência, Estudos e Ações sobre Crianças e Adolescentes, 1998.

SANTOS, José Vicente Tavares dos. A agonia da vida: mortes violentas entre a juventude do país do futuro. In: Marcus Gonçalves da Cruz e Eduardo Cerqueira Batitucci (Org.). Homicídios no Brasil. Rio de Janeiro: FGV, 2007. 2009.

SOUZA, Edinilsa Ramos de; JORGE, Maria Helena Prado de Mello. Impacto da violência na infância e adolescência brasileiras: magnitude da morbimortabilidade. In: Violência faz mal à saúde. Cláudia Araújo de Lima (Coord.) et al. Brasília: Ministério da Saúde, 2006.

TRINDADE, Jorge. Delinquência juvenil: uma abordagem transdisciplinar. 2 ed. Porto Alegre: Livraria do Advogado, 1996.

ZIMERMAN, David. Os quatro vínculos: amor, ódio, conhecimento reconhecimento na psicanálise e em nossas vidas. Porto Alegre: Artmed, 2010.

WORLD FEDERATION FOR INFANT MENTAL HEALTH (WHOM), 2002.Relatório do Dia Mundial da Saúde Mental, 2002. 